\title{
SIMPLE, MILD, AND HIGHLY EFFICIENT SYNTHESIS OF 2-SUBSTITUTED BENZIMIDAZOLES AND BIS- BENZIMIDAZOLES
}

\author{
Bilge Eren ${ }^{\mathrm{a}, *}$ and Yunus Bekdemir ${ }^{\mathrm{b}}$ \\ aFaculty of Science and Arts, Department of Chemistry, Bilecik Seyh Edebali University, 11210 Bilecik, Turkey \\ ${ }^{b}$ Faculty of Science and Arts, Canik Basarı University, 55080 Canik, Samsun, Turkey
}

Recebido em 12/09/2013; aceito em 02/12/2013; publicado na web em 27/03/2014

\begin{abstract}
A new convenient method for preparation of 2-substituted benzimidazoles and bis-benzimidazoles is presented. In this method, $o$-phenylenediamines were condensed with bisulfite adducts of various aldehydes and di-aldehydes under neat conditions by microwave heating. The results were also compared with results of synthesis by conventional heating under reflux. Structures of the products were confirmed by infrared, ${ }^{1} \mathrm{H}$ - and ${ }^{13} \mathrm{C}-\mathrm{NMR}$ spectroscopy. Short reaction times, good yields, easy purification of products, and mild reaction conditions are the main advantages of this method.
\end{abstract}

Keywords: benzimidazole; microwave heating; synthesis.

\section{INTRODUCTION}

Natural biological substances such as purine bases and vitamin B12 include benzimidazole moiety in their structure. Several benzimidazole derivatives are reported to exhibit antimicrobial, ${ }^{1-3}$ anticancer, ${ }^{4,5}$ antifungal, ${ }^{6,7}$ antiparasitic, ${ }^{8}$ antiviral, ${ }^{9}$ anti-inflammatory, ${ }^{10}$ and antihistaminic ${ }^{11}$ activities. Therefore, methods for their preparations are important for synthetic organic chemists and biologists. There are two fundamental methods for the preparation of 2-substituted benzimidazole derivatives. One method is condensation of $o$-phenylenediamines with corresponding carboxylic acids via a strong acid, ${ }^{12-15}$ PPA, ${ }^{15-17}$ or a catalyst. ${ }^{18,19}$ High-temperature-pressurised systems ${ }^{20}$ or microwaves (MWs) ${ }^{17,18}$ are also used to promote these reactions. The other method is condensation of $o$-phenylenediamines with aldehydes under oxidative conditions. ${ }^{15,21}$ Various reagents such as $\mathrm{I}_{2} / \mathrm{KI}$, ${ }^{22}$ In $(\mathrm{OTf})_{3},{ }^{23}$ nitrobenzene, ${ }^{24}$ benzoquinone,,${ }^{25}$ Oxone, ${ }^{26} \mathrm{Fe}\left(\mathrm{HSO}_{4}\right)_{3}{ }^{27}$ and atmospheric air ${ }^{28}$ are used for this purpose. Nevertheless, some of these reported methods have limitations such as low yields, high reaction temperatures, long reaction times, harsh reaction conditions, purification difficulties, and formation of by-products.

In contrast to a conventional heating source, MW energy couples directly with polar molecules or ions and leads to a rapid rise in the temperature of reaction medium. ${ }^{29,30}$ Reactions that require hours or even days using conventional heating can usually be completed in minutes or seconds using MWs. Several reactions have been performed under MW-assisted conditions with significant rate enhancements, improved yield, and selectivity. ${ }^{30}$

Owing to the immense importance of the benzimidazole moiety and the aforementioned limitations in their synthesis, we believed it would be worthwhile to develop a practical method for their synthesis. Aldehyde bisulfite adducts were first used by Ridely et al. ${ }^{31}$ for the preparation of some benzimidazoles and aza-analogs under classical reflux conditions. This article reports the first MW-assisted neat (to right doughy consistency) synthesis of some 2-substituted benzimidazoles and bis-benzimidazoles from a wide variety of aldeyde and dialdehyde bisulfite adducts (Scheme 1). The observed yields under classical heating (24-70\%) is increased to higher values when the reaction is performed under MW-assisted conditions (65-95\%). The increase in the reaction rates were also in a good range.

*e-mail: bilge.eren@bilecik.edu.tr<smiles></smiles>

Scheme 1. Synthesized benzimidazole structures

\section{EXPERIMENTAL}

The 2-substituted benzimidazole and bis-benzimidazole derivatives were synthesized under $180 \mathrm{~W}$ MW irradiation. A domestic microwave (Bosch HMT $812 \mathrm{C}$ ) oven that was modified to accomodate a reflux system and an internal camera was used in all syntheses. MWs at $2450 \mathrm{MHz}$ frequency, which corresponds to a wavelength of 12.2 $\mathrm{cm}$ and an energy of $0.23 \mathrm{cal} / \mathrm{mol}(=0.94 \mathrm{~J} / \mathrm{mol})$, were used. All raw materials and solvents were purchased from Merck or Sigma-Aldrich and were used without further purification. IR spectra were recorded on a Bruker Vertex 80v spectrometer. The ${ }^{1} \mathrm{H}-(400 \mathrm{MHz})$ and ${ }^{13} \mathrm{C}-$ (100 MHz) NMR spectra were recorded on a Bruker Avence II-400 MHz NMR spectrometer using tetramethylsilane (TMS) as an internal standard and DMSO- $d_{6}$ as solvent. Melting points were measured with a Gallenkamp electrothermal apparatus and are uncorrected. Reactions were monitored by thin-layer chromatography (TLC) on plates procured from Merck.

\section{General procedure for conversion of aldehydes to $\mathrm{NaHSO}_{3}$ adducts}

Equivalent moles $(50 \mathrm{mmol})$ of aldehyde and sodium hydrogen sulfite were dissolved in ethanol $(25 \mathrm{~mL})$ and water $(25 \mathrm{~mL})$, respectively. For dialdehydes, mole ratio of dialdehyde/sodium hydrogen sulfite was 1:2. Sodium hydrogen sulfite solution was added in portions to a vigorously stirred solution of aldehyde in an ice bath and the stirring was continued for $1 \mathrm{~h}$ at room temperature. The mixture was filtered and dried in vacuo to provide the crude aldeyde-bisulfite adduct (yield $=60-95 \%$ ).

General procedure for the synthesis of 2-substituted benzimidazoles and bis-benzimidazoles

\section{Microwave Method}

Substituted $o$-phenylenediamine (for benzimidazoles, $2 \mathrm{mmol}$; bisbenzimidazoles, $4 \mathrm{mmol}$ ) and the appropriate aldeyde-bisulfite 
adduct $(2.1 \mathrm{mmol})$ were ground thoroughly and transferred to a 50 $\mathrm{mL}$ flask. After adding a few drops of DMF, the mixture was irradiated in a microwave oven at $180 \mathrm{~W}$. The progress of the reaction was monitored by TLC, with a mixture of ethanol and water $(9: 1)$ as the eluent. On completion, the reaction mixture was cooled, ice-cold distilled water was added, and stirred for a while wherein a precipitate was observed. The precipitate was collected by filtration, washed with water, dried, and recrystallised from ethanol/water.

\section{Classical Heating Method}

Substituted $o$-phenylenediamine (for benzimidazoles, $2 \mathrm{mmol}$; bisbenzimidazoles, $4 \mathrm{mmol}$ ) and the appropriate aldehyde-bisulfite adduct $(2.1 \mathrm{mmol})$ were ground thoroughly and transferred to a 50 $\mathrm{mL}$ flask. The mixture was refluxed in DMF $(20 \mathrm{~mL})$ over a hotplate stirrer. The progress of the reaction was monitored by TLC. After completion of the reaction, the product was purified as described above.

\section{Selected Data for Synthesized Compounds}

Data for 1. IR $\left(v, \mathrm{~cm}^{-1}\right)$ : 3150-2540, 1600, 1548, 1319, 1268; ${ }^{1} \mathrm{H}$ NMR (400 MHz, DMSO- $d_{6}$ ): $\delta$ 7.17-7.21 (m, 2H, H-5, H-6), 7.407.67 (m, 5H, H-2', H-3', H-4', H-5', H-6'), 8.15-8.18 (m, 2H, H-4, $\mathrm{H}-7) 12.89$ (s, $1 \mathrm{H}, \mathrm{NH}) ;{ }^{13} \mathrm{C}$ NMR (400 MHz, DMSO- $d_{6}$ ): 118.80, 121.60, 126.40, 128.80, 129.80, 130.10, 134.90, 151.20

Data for 4. IR $\left(v, \mathrm{~cm}^{-1}\right)$ : 3259, 3080-2500, 1676, 1600, 1310, 1268; ' ${ }^{\mathrm{H}} \mathrm{NMR}\left(400 \mathrm{MHz}, \mathrm{DMSO}-d_{6}\right)$ : $\delta$ 6.99-7.03 (m, 2H, H-3', H-5'), 7.27 (bs, 2H, H-5, H-6), 7.64 (bs, 2H, H-4, H-7), 7.37 (t, J=7.2 $\mathrm{Hz}, 1 \mathrm{H}, \mathrm{H}-4^{\prime}$ ), 8.03 (d, J= $8 \mathrm{~Hz}, 2 \mathrm{H}, \mathrm{H}-6^{\prime}$ ), 13.10 (s, 2H, NH, OH); ${ }^{13} \mathrm{C}$ NMR (400 MHz, DMSO- $d_{6}$ ): 115.38, 116.05, 117.01, 121.05, $123.24,128.80,131.72,140.50,154.42,156.03$

Data for 10. IR $\left(v, \mathrm{~cm}^{-1}\right)$ : 3080-2528, 1625, 1574, 1319, 1242, 578 ; ${ }^{1} \mathrm{H}$ NMR (400 MHz, DMSO- $\left.d_{6}\right): \delta 7.21(\mathrm{dd}, J=6.0,4.0 \mathrm{~Hz}, 2 \mathrm{H}$, H-5, H-6), 7.24 (dd, J=4.0, 4.0 Hz, 1H, H-3'), 7.54 (d, J=4.0 Hz, $1 \mathrm{H}, \mathrm{H}-7), 7.60$ (d, $J=4.0 \mathrm{~Hz}, \mathrm{H}-4), 7.73$ (dd, $J=6.0,4.0 \mathrm{~Hz}, 1 \mathrm{H}$, $\left.\mathrm{H}-4^{\prime}\right), 7.85$ (dd, $\left.J=4.0,4.0 \mathrm{~Hz}, 1 \mathrm{H}, \mathrm{H}-2^{\prime}\right), 13.02(\mathrm{~s}, 1 \mathrm{H}, \mathrm{NH}) ;{ }^{13} \mathrm{C}$ NMR (400 MHz, DMSO- $\left.d_{6}\right)$ : 111.11, 118.48, 121.86, 122.55, 126.69, $128.28,128.75,133.59,134.67,143.50,147.00$

Data for 13. IR $\left(v, \mathrm{~cm}^{-1}\right)$ : 3145-2666, 2925, 2856, 1621, 1588, 1313, 1273; ${ }^{1} \mathrm{H}$ NMR (400 MHz, DMSO- $\left.d_{6}\right): \delta 2.36\left(\mathrm{~s}, 3 \mathrm{H}, \mathrm{CH}_{3}\right)$, 7.14-7.21 (m, 2H, H-5, H-6), 7.34 (d, J= 8 Hz, 2H, H-3', H-5'), 7.50 (d, $J=7.2,1 \mathrm{H}, \mathrm{H}-7$ ), 7.63 (d, $J=7.6,1 \mathrm{H}, \mathrm{H}-4), 8.05$ (d, $J=8 \mathrm{~Hz}, 2 \mathrm{H}$, H-2', H-6') 12.82 (s, 1H, NH); ${ }^{13} \mathrm{C}$ NMR (400 MHz, DMSO- $d_{6}$ ): $21.41,119.13,122.02,122.79,127.87,126.83,129.96,135.37$, $140.03,151.82$

Data for 16. IR $\left(v, \mathrm{~cm}^{-1}\right)$ : 3146-2666, 2920, 2843, 1610, 1585, 1250,$1182 ;{ }^{1} \mathrm{H}$ NMR (400 MHz, DMSO- $\left.d_{6}\right): \delta 3.79\left(\mathrm{~s}, 3 \mathrm{H}, \mathrm{OCH}_{3}\right.$ ), 6.93 (d, $J=8.4$ Hz, 2H, H-3', H-5'), 7.08 (dd, J= 6, 8.3 Hz, 2H, H-5, H-6), 7.39 (bs, 1H, H-7), 7.56 (bs, 1H, H-4), 8.05 (d, J= 8.4 Hz, 2H, H-2', H-6') 12.38 (bs, $1 \mathrm{H}, \mathrm{NH}) ;{ }^{13} \mathrm{C}$ NMR (400 MHz, DMSO- $d_{6}$ ): $55.41,114.24,118.67,122.25,123.03,128.32,136.25,151.98,160.93$

Data for 22. IR (v, $\left.\mathrm{cm}^{-1}\right)$ : 3052-2544, 1602, 1586, 1320, 1272; ${ }^{1} \mathrm{H}$ NMR (400 MHz, DMSO- $\left.d_{6}\right)$ : $\delta 7.20(\mathrm{dd}, J=6,3.2 \mathrm{~Hz}, 2 \mathrm{H}, \mathrm{H}-5$, H-6), 7.59 (bs, 2H, H-4, H-7), 7.61 (d, J= 8.4 Hz, 2H, H-3', H-5'), 8.18 (d, $\left.J=8.8 \mathrm{~Hz}, 2 \mathrm{H}, \mathrm{H}-2^{\prime}, \mathrm{H}-6{ }^{\prime}\right), 12.95$ (bs, $\left.1 \mathrm{H}, \mathrm{NH}\right) ;{ }^{13} \mathrm{C} \mathrm{NMR}(400$ MHz, DMSO- $\left.d_{6}\right): 122.78,128.59,129.49,129.51,134.96,150.62$

Data for 23. IR $\left(v, \mathrm{~cm}^{-1}\right)$ : 3100-2500, 1624, 1586, 1304, 1224, $731 ;{ }^{1} \mathrm{H}$ NMR (400 MHz, DMSO- $d_{6}$ ): $\delta 7.23(\mathrm{dd}, J=8.4,2 \mathrm{~Hz}, 1 \mathrm{H}$, H-6), 7.59 (bs, 1H, H-7), 7.62 (s, 1H, H-4), 7.63 (d, J= $8.8 \mathrm{~Hz}, 2 \mathrm{H}$, $\left.\mathrm{H}-3^{\prime}, \mathrm{H}-5^{\prime}\right), 8.16$ (d, J=8.8 Hz, 2H, H-2', H-6 $) ;{ }^{13} \mathrm{C} \mathrm{NMR}(400 \mathrm{MHz}$, DMSO- $\left.d_{6}\right): 123.07,127.08,128.74,129.01,129.60,135.35,152.62$

Data for 24. IR $\left(v, \mathrm{~cm}^{-1}\right)$ : 3200-2615, 2918, 2865, 1629, 1602, 1314, 1229; ${ }^{1} \mathrm{H}$ NMR (400 MHz, DMSO- $d_{6}$ ): $\delta 2.49$ (s, 3H, $\mathrm{CH}_{3}$ ), 7.02 (d, J= 8 Hz, 1H, H-6), 7.39 (bs, 1H, H-4), 7.47 (bs, 1H, H-7), $7.60\left(\mathrm{~d}, J=8.8 \mathrm{~Hz}, 2 \mathrm{H}, \mathrm{H}-3^{\prime}, \mathrm{H}-5^{\prime}\right), 8.14$ (d, $J=8.8 \mathrm{~Hz}, 2 \mathrm{H}, \mathrm{H}-2^{\prime}$, H-6'), 12.82 (bs, $1 \mathrm{H}, \mathrm{NH}) ;{ }^{13} \mathrm{C}$ NMR (400 MHz, DMSO- $d_{6}$ ): 21.78, $124.50,128.45,129.47,129.62,134.73,138.10,150.50$

Data for 25. IR (v, $\left.\mathrm{cm}^{-1}\right)$ : 3055, 2944, 1605, 1524, 1328, 1241; ${ }^{1} \mathrm{H}$ NMR (400 MHz, DMSO- $d_{6}$ ): $\delta 3.86\left(\mathrm{~s}, 3 \mathrm{H}, \mathrm{NCH}_{3}\right), 7.31-7.22(\mathrm{~m}$, 2H, H-5, H-6), 7.68-7.53 (m, 5H, H-2', H-3', H-4', H-5', H-6'), 7.84 (dd, $J=7.2,2.4 \mathrm{~Hz}, 2 \mathrm{H}, \mathrm{H}-4, \mathrm{H}-7)$; ${ }^{13} \mathrm{C}$ NMR (400 MHz, DMSO- $\left.d_{6}\right)$ : $32.10,111.01,119.44,122.39,122.81,129.11,129.75,130.09$, $130.59,137.03,142.92,153.47$

Data for 27. IR (v, $\left.\mathrm{cm}^{-1}\right)$ : 3032, 2970, 2812, 1610, 1570, 1320, 1277; ${ }^{1} \mathrm{H}$ NMR (400 MHz, DMSO- $\left.d_{6}\right): \delta 2.98\left(\mathrm{~s}, 6 \mathrm{H}, \mathrm{N}\left(\mathrm{CH}_{3}\right)_{2}\right)$, 3.84 (s, 3H, $\left.\mathrm{NCH}_{3}\right), 6.84$ (d, J=9.2 Hz, 2H, H-3', H-5'), 7.24-7.16 (m, 2H, H-5, H-6), 7.60 (d, J=7.6 Hz, 1H, H-4), 7.50 (d, J=8.8 Hz, 1H, H-7), 7.68 (d, J=8.8 Hz, 2H, H-2', H-6'); ${ }^{13} \mathrm{C}$ NMR (400 MHz, DMSO- $d_{6}$ ): $32.20,40.20,110.54,112.10,117.41,118.81,122.05$, $130.60,137.12,143.07,151.37,154.28$

Data for 29. IR (v, $\left.\mathrm{cm}^{-1}\right)$ : 3040, 2944, 2859, 1611, 1482, 1325 , $1249 ;{ }^{1} \mathrm{H}$ NMR (400 MHz, DMSO- $\left.d_{6}\right): \delta 2.39$ (s, 3H, $\mathrm{CH}_{3}$ ), $3.84(\mathrm{~s}$, $3 \mathrm{H}, \mathrm{NCH}_{3}$ ), 7.29-7.21 (m, 2H, H-5, H-6), 7.37 (d, J=8 Hz, 2H, H-3', H-5'), 7.66 (d, $J=7.6 \mathrm{~Hz}, 1 \mathrm{H}, \mathrm{H}-4), 7.58$ (d, $J=7.6 \mathrm{~Hz}, 1 \mathrm{H}, \mathrm{H}-7$ ), 7.73 (d, $\left.J=8 \mathrm{~Hz}, 2 \mathrm{H}, \mathrm{H}-2^{\prime}, \mathrm{H}-6{ }^{\prime}\right) ;{ }^{13} \mathrm{C}$ NMR (400 MHz, DMSO- $\left.d_{6}\right)$ : 21.40, 32.48, 110.91, 119.31, 122.31, 122.66, 129.74, 129.65, 129.68, 137.02, 139.78, 142.92, 153.56 .

Data for 30. IR (v, $\left.\mathrm{cm}^{-1}\right): 3047,2948,2843,1613,1536,1379$, $1249 ;{ }^{1} \mathrm{H}$ NMR (400 MHz, DMSO- $\left.d_{6}\right): \delta 3.83$ (s, $3 \mathrm{H}, \mathrm{NCH}_{3}$ ), 3.84 (s, 3H, $\mathrm{OCH}_{3}$ ), 7.11 (d, J=8.8 Hz, 2H, H-3', H-5'), 7.28-7.19 (m, 2H, H-5, H-6), 7.65 (d, J=7.2 Hz, 1H, H-4), 7.56 (d, J=7.2 Hz, 1H, H-7), 7.79 (d, $\left.J=8.8 \mathrm{~Hz}, 2 \mathrm{H}, \mathrm{H}-2^{\prime}, \mathrm{H}-6{ }^{\prime}\right) . ;{ }^{13} \mathrm{C} \mathrm{NMR}(400 \mathrm{MHz}$, DMSO- $\left.d_{6}\right)$ : $32.09,55.77,110.81,114.55,119.17,122.24,122.49$, $122.83,131.22,137.03,142.93,153.47,160.75$

Data for 33. IR $\left(v, \mathrm{~cm}^{-1}\right)$ : 3163-2544, 1623, 1587, 1322, 1269; ${ }^{1} \mathrm{H}$ NMR (400 MHz, DMSO- $\left.d_{6}\right)$ : $\delta 7.22$ (bs, 2H, H-5, H-6), 7.56 (d, $J=6.4 \mathrm{~Hz}, 1 \mathrm{H}, \mathrm{H}-7$ ), 7.69 (d, J=6.8 Hz, 1H, H-4), 8.33 (s, 1H, H-2'), $13.03(\mathrm{~s}, 1 \mathrm{H}, \mathrm{NH}) ;{ }^{13} \mathrm{C}$ NMR (400 MHz, DMSO- $\left.d_{6}\right)$ : $119.43,123.31$, $127.36,131.57,135.52,151.02$

\section{RESULTS AND DISCUSSION}

Aldehyde bisulfite adducts were easly prepared according to the conventional method as described in the experimental section. They are whitish solids that remain stable for a long time when stored in a refrigerator. The compounds, 2-substituted benzimidazoles (1-32) and bis-benzimidazoles (33-36) were synthesized via condensation of $o$-phenylenediamines with aldehyde bisulfite adducts under MW irradiation. MW reactions were performed under a neat protocol, using only a few drops of DMF to homogenize the reaction mixture. Eight aromatic aldehydes, a dialdehyde, and four $o$-phenylenediamines, including those bearing electron-donating or electron-withdrawing substituents, were used to investigate the efficiency of the method. The synthetic schemes for the synthesis of benzimidazoles and bisbenzimidazoles are described in Scheme 2 and Scheme 3, respectively.

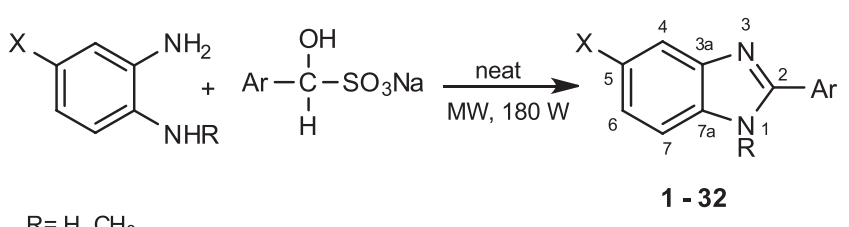

$\mathrm{R}=\mathrm{H}, \mathrm{CH}_{3}$

$\mathrm{X}=\mathrm{H}, \mathrm{Cl}, \mathrm{CH}_{3}$

$\mathrm{Ar}=\mathrm{C}_{6} \mathrm{H}_{5}, 2-\mathrm{HOC}_{6} \mathrm{H}_{4}, 4-\mathrm{Me}_{2} \mathrm{NC}_{6} \mathrm{H}_{4}, 2-T h i o p h e n y l, 4-\mathrm{MeC}_{6} \mathrm{H}_{4}$, 4- $\mathrm{MeOC}_{6} \mathrm{H}_{4}$, 2-Hydroxy-1-naphthyl, 4- $\mathrm{ClC}_{6} \mathrm{H}_{4}$

Scheme 2. Synthetic procedure for the benzimidazole derivatives 


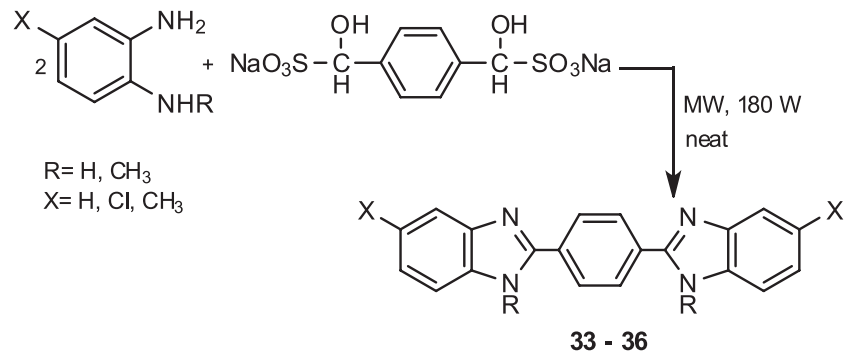

Scheme 3. Synthetic procedure for the bis-benzimidazole derivatives

The current experimental results are summarized in Table 1 and Table 2. Benzimidazoles bearing either electron-donating (entries 4-9 and 13-18) or electron-withdrawing substituents (entries 22-24) were successfully produced in very short times with excellent yields. Considering the reaction times, a significant effect of the substituents on either aldehydes or $o$-phenylenediamines were not observed. A methyl substitution on nitrogen atom of $o$-phenylenediamine decreased the rate, possibly because of steric hindrance (entries 25-32). The reactions with $\mathrm{N}$-methyl $o$-phenylenediamine were completed in longer times with lower yields compared with their unsubstituted analogues (entries 1, 4, 7, 10, 13, 16, 19, and 22).

The developed protocol was specifically significant for the synthesis of bisbenzimidazoles. As indicated in the literature, their synthesis by conventional heating required prolonged reaction times ${ }^{32-34}$ and harsh conditions such as high temperatures,${ }^{20}$ high pressures,${ }^{20}$ and toxic solvents. ${ }^{33-35}$ In this study, the synthesis was performed in short times (e.g., 10 min for compound 33) with good yields (80-92\%) under mild (MW/180 W) and solvent-free conditions.

A mechanism have been proposed for the preperation of benzimidazoles based on some information in the literature ${ }^{27,36}$ (Scheme 4). The reaction begins with the nucleophilic attack of the amine group on the $o$-phenylenediamine to the carbon atom of aldehyde bisulfite adduct. One mole of water is eliminated. Subsequently, the resulting alkyl sulfonate further reacts with the other amine group of $o$-phenylenediamine, resulting in the formation of dihydroimidazole intermediate. Finally, aromatization gives benzimidazole nucleus. Dipolar transition state structures $\left(\mathrm{TS}_{1}\right.$ and $\left.\mathrm{TS}_{2}\right)$ are formed in the course of the reaction. As indicated in the literature, ${ }^{29}$ this type of reactions are expected to proceed at a faster rate and provide high yields under MW irradiation.

Table 1. Physical data and reaction times of the synthesized benzimidazoles under microwave irradiation

\begin{tabular}{|c|c|c|c|c|c|c|}
\hline \multirow{3}{*}{ Entry } & \multicolumn{3}{|c|}{ Compound } & \multirow{3}{*}{ m.p. $\left({ }^{\circ} \mathrm{C}\right)$} & \multirow{3}{*}{$\begin{array}{l}\text { Reaction Time } \\
\quad(\min )\end{array}$} & \multirow{3}{*}{ Yield (\%) } \\
\hline & & & & \\
\hline & $\mathrm{Ar}$ & $\mathrm{R}$ & $\mathrm{X}$ & & & \\
\hline 1 & $\mathrm{C}_{6} \mathrm{H}_{5}$ & $\mathrm{H}$ & $\mathrm{H}$ & 290-292 & 8 & 85 \\
\hline 2 & $\mathrm{C}_{6} \mathrm{H}_{5}$ & $\mathrm{H}$ & $\mathrm{Cl}$ & 206-208 & 4 & 76 \\
\hline 3 & $\mathrm{C}_{6} \mathrm{H}_{5}$ & $\mathrm{H}$ & $\mathrm{CH}_{3}$ & $234-236$ & 2 & 83 \\
\hline 4 & 2- $-\mathrm{HOC}_{6} \mathrm{H}_{4}$ & $\mathrm{H}$ & $\mathrm{H}$ & $237-238$ & 4 & 90 \\
\hline 5 & $2-\mathrm{HOC}_{6} \mathrm{H}_{4}$ & $\mathrm{H}$ & $\mathrm{Cl}$ & $276-277$ & 2 & 85 \\
\hline 6 & $2-\mathrm{HOC}_{6} \mathrm{H}_{4}$ & $\mathrm{H}$ & $\mathrm{CH}_{3}$ & $252-254$ & 2 & 84 \\
\hline 7 & $4-\mathrm{Me}_{2} \mathrm{NC}_{6} \mathrm{H}_{4}$ & $\mathrm{H}$ & $\mathrm{H}$ & $292-294$ & 16 & 77 \\
\hline 8 & $4-\mathrm{Me}_{2} \mathrm{NC}_{6} \mathrm{H}_{4}$ & $\mathrm{H}$ & $\mathrm{Cl}$ & $243-246$ & 20 & 79 \\
\hline 9 & $4-\mathrm{Me}_{2} \mathrm{NC}_{6} \mathrm{H}_{4}$ & $\mathrm{H}$ & $\mathrm{CH}_{3}$ & $249-251$ & 12 & 81 \\
\hline 10 & 2-Thiophenyl & $\mathrm{H}$ & $\mathrm{H}$ & $333-334$ & 6 & 75 \\
\hline 11 & 2-Thiophenyl & $\mathrm{H}$ & $\mathrm{Cl}$ & 223 & 20 & 64 \\
\hline 12 & 2-Thiophenyl & $\mathrm{H}$ & $\mathrm{CH}_{3}$ & $248-249$ & 6 & 76 \\
\hline 13 & $4-\mathrm{MeC}_{6} \mathrm{H}_{4}$ & $\mathrm{H}$ & $\mathrm{H}$ & $275-276$ & 25 & 87 \\
\hline 14 & 4- $\mathrm{MeC}_{6} \mathrm{H}_{4}$ & $\mathrm{H}$ & $\mathrm{Cl}$ & $233-235$ & 10 & 85 \\
\hline 15 & $4-\mathrm{MeC}_{6} \mathrm{H}_{4}$ & $\mathrm{H}$ & $\mathrm{CH}_{3}$ & $189-190$ & 25 & 81 \\
\hline 16 & 4- $\mathrm{MeOC}_{6} \mathrm{H}_{4}$ & $\mathrm{H}$ & $\mathrm{H}$ & $225-226$ & 10 & 89 \\
\hline 17 & 4- $\mathrm{MeOC}_{6} \mathrm{H}_{4}$ & $\mathrm{H}$ & $\mathrm{Cl}$ & $179-181$ & 5 & 87 \\
\hline 18 & 4- $\mathrm{MeOC}_{6} \mathrm{H}_{4}$ & $\mathrm{H}$ & $\mathrm{CH}_{3}$ & $85-87$ & 5 & 80 \\
\hline 19 & 2-Hydroxy-1-naphthyl & $\mathrm{H}$ & $\mathrm{H}$ & $239-241$ & 6 & 80 \\
\hline 20 & 2-Hydroxy-1-naphthyl & $\mathrm{H}$ & $\mathrm{Cl}$ & $233-235$ & 8 & 95 \\
\hline 21 & 2-Hydroxy-1-naphthyl & $\mathrm{H}$ & $\mathrm{CH}_{3}$ & $218-220$ & 8 & 81 \\
\hline 22 & $4-\mathrm{ClC}_{6} \mathrm{H}_{4}$ & $\mathrm{H}$ & $\mathrm{H}$ & $289-290$ & 2 & 88 \\
\hline 23 & 4- $\mathrm{ClC}_{6} \mathrm{H}_{4}$ & $\mathrm{H}$ & $\mathrm{Cl}$ & $228-230$ & 2 & 81 \\
\hline 24 & 4- $\mathrm{ClC}_{6} \mathrm{H}_{4}$ & $\mathrm{H}$ & $\mathrm{CH}_{3}$ & $220-222$ & 6 & 88 \\
\hline 25 & $\mathrm{C}_{6} \mathrm{H}_{5}$ & $\mathrm{Me}$ & $\mathrm{H}$ & $91-92$ & 20 & 65 \\
\hline 26 & $2-\mathrm{HOC}_{6} \mathrm{H}_{4}$ & $\mathrm{Me}$ & $\mathrm{H}$ & $164-165$ & 6 & 80 \\
\hline 27 & $4-\mathrm{Me}_{2} \mathrm{NC}_{6} \mathrm{H}_{4}$ & $\mathrm{Me}$ & $\mathrm{H}$ & $155-156$ & 20 & 71 \\
\hline 28 & 2-Thiophenyl & $\mathrm{Me}$ & $\mathrm{H}$ & $71-73$ & 8 & 77 \\
\hline 29 & 4- $\mathrm{MeC}_{6} \mathrm{H}_{4}$ & $\mathrm{Me}$ & $\mathrm{H}$ & $122-124$ & 25 & 74 \\
\hline 30 & 4- $\mathrm{MeOC}_{6} \mathrm{H}_{4}$ & $\mathrm{Me}$ & $\mathrm{H}$ & $115-117$ & 10 & 80 \\
\hline 31 & 2-Hydroxy-1-naphthyl & $\mathrm{Me}$ & $\mathrm{H}$ & $280-283$ & 10 & 72 \\
\hline 32 & $4-\mathrm{ClC}_{6} \mathrm{H}_{4}$ & $\mathrm{Me}$ & $\mathrm{H}$ & $109-110$ & 20 & 70 \\
\hline
\end{tabular}


Table 2. Physical data and reaction times for the synthesized bisbenzimidazoles under microwave irradiation

\begin{tabular}{|c|c|c|c|c|c|}
\hline \multirow{3}{*}{ Entry } & & & \multirow{3}{*}{ m.p. $\left({ }^{\circ} \mathrm{C}\right)$} & \multirow{3}{*}{ Reaction Time (min) } & \multirow{3}{*}{ Yield (\% } \\
\hline & & & & & \\
\hline & $\mathrm{R}$ & $\mathrm{X}$ & & & \\
\hline 33 & $\mathrm{H}$ & $\mathrm{H}$ & $>350$ & 10 & 87 \\
\hline 34 & $\mathrm{H}$ & $\mathrm{Cl}$ & $>350$ & 20 & 92 \\
\hline 35 & $\mathrm{H}$ & $\mathrm{CH}_{3}$ & 350 dec. & 25 & 89 \\
\hline 36 & $\mathrm{CH}_{3}$ & $\mathrm{H}$ & $281-283$ & 35 & 80 \\
\hline
\end{tabular}

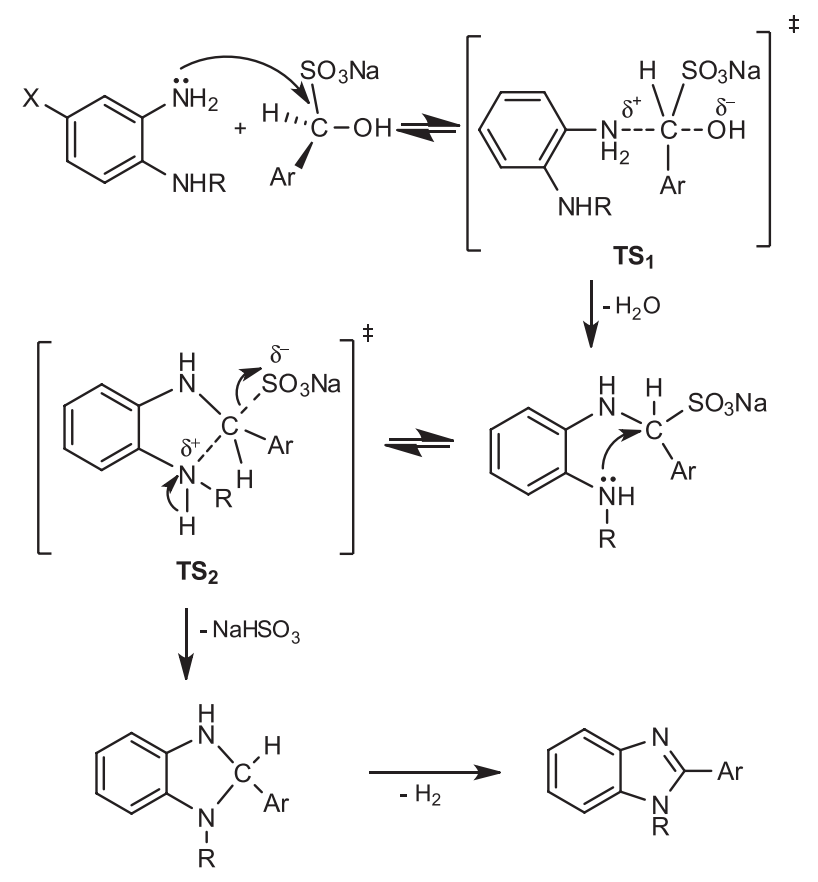

Scheme 4. Plausible mechanism for the synthesis of benzimidazoles

To compare the MW-assisted synthesis method with the classical heating method, the synthesis of some benzimidazoles were also performed under reflux in DMF. Related experimental results are shown in Table 3. It is clear that in all cases much shorter reaction times and higher yields were achieved under MW irradiation compared with classical heating. For example, with conventional heating, 2-(5-chlorobenzimidazolyl)phenol 5 was obtained in $45 \%$ yield in 120 min; under MW conditions, after 2 min the yield of the reaction was $85 \%$. Similarly, classical and MW-assisted sysnthesis yielded 2-(5-chlorophenyl)benzimidazole 22 in 43\% (180 min) and 77\% (2 min), respectively. The MW method also provided good results for bisbenzimidazole derivatives. For example, 1,4-bis(2-benzimidazolyl)benzene 33, was synthesized in 300 min with $56 \%$ yield by classical heating method; using MWs, it was obtained in $10 \mathrm{~min}$ with $87 \%$ yield.

The structures of the products were confirmed by IR, ${ }^{1} \mathrm{H}-$, and ${ }^{13} \mathrm{C}-\mathrm{NMR}$, and the details are given in the experimental section. The IR spectra of the synthesized $1 H$-benzimidazole derivatives show strong bands in the $3200-2400 \mathrm{~cm}^{-1}$ region, which is a characteristic of such compounds and indicate $\mathrm{N}-\mathrm{H} \cdots \mathrm{N}$ type hydrogen bonds. ${ }^{37}$ In addition, the absence of any band corresponding to $\mathrm{N}-\mathrm{H}$ stretching vibrations, in the $3200-3600 \mathrm{~cm}^{-1}$ region indicates that the $o$-phenylenediamine has reacted with the aldehyde bisulfite adducts and formed the benzimidazole ring system. Moreover,
Table 3. Comparison of microwave and classical heating for synthesis of some benzimidazoles

\begin{tabular}{ccccc}
\hline & \multicolumn{2}{c}{ Classical heating $^{\mathrm{a}}$} & \multicolumn{2}{c}{ Microwave conditions } \\
\cline { 2 - 5 } Entry & $\begin{array}{c}\text { React. Time } \\
(\mathrm{min})\end{array}$ & $\begin{array}{c}\text { Yield } \\
(\%)\end{array}$ & $\begin{array}{c}\text { React. Time } \\
(\mathrm{min})\end{array}$ & $\begin{array}{c}\text { Yield } \\
(\%)\end{array}$ \\
\hline $\mathbf{1}$ & 120 & 70 & 8 & 85 \\
$\mathbf{4}$ & 120 & 55 & 4 & 90 \\
$\mathbf{5}$ & 120 & 45 & 2 & 85 \\
$\mathbf{7}$ & 180 & 55 & 16 & 77 \\
$\mathbf{1 0}$ & 120 & 66 & 6 & 75 \\
$\mathbf{1 3}$ & 180 & 63 & 25 & 87 \\
$\mathbf{1 4}$ & 180 & 65 & 10 & 85 \\
$\mathbf{1 5}$ & 180 & 56 & 25 & 81 \\
$\mathbf{1 6}$ & 180 & 65 & 10 & 89 \\
$\mathbf{1 7}$ & 180 & 68 & 5 & 87 \\
$\mathbf{1 8}$ & 180 & 66 & 5 & 80 \\
$\mathbf{1 9}$ & 150 & 70 & 6 & 80 \\
$\mathbf{2 2}$ & 180 & 43 & 2 & 88 \\
$\mathbf{2 3}$ & 180 & 53 & 2 & 81 \\
$\mathbf{2 4}$ & 180 & 54 & 6 & 88 \\
$\mathbf{2 5}$ & 300 & 24 & 20 & 65 \\
$\mathbf{2 6}$ & 240 & 38 & 20 & 71 \\
$\mathbf{3 3}$ & 300 & 56 & 10 & 87 \\
$\mathbf{3 6}$ & 360 & 49 & 35 & 80 \\
\hline
\end{tabular}

${ }^{\mathrm{a}}$ Reflux in DMF; ${ }^{\mathrm{N}} \mathrm{Neat}$ conditions under $180 \mathrm{~W}$ microwave irradiation.

the IR spectra of the compounds include strong/medium bands in the $1650-1400 \mathrm{~cm}^{-1}$ region and correspond to the $\mathrm{C}=\mathrm{C}$ and $\mathrm{C}=\mathrm{N}$ stretching vibrations. ${ }^{37-40}{ }^{1} \mathrm{H}$ - and ${ }^{13} \mathrm{C}$-NMR results also support the formation of the synthesized compounds. ${ }^{41,42}$ The NH protons of compounds containing $1 \mathrm{H}$-benzimidazole ring appear as broad singlets at $12.0-13.3 \mathrm{ppm}$. Because of the 1,3-tautomerisation ${ }^{41}$ $3 \mathrm{a} / 7 \mathrm{a}, 4 / 7$, and $5 / 6$ positions of the unsubstituted benzimidazoles are equivalent and generally appears at the same region in the ${ }^{1} \mathrm{H}$ - and ${ }^{13} \mathrm{C}$ - NMR spectra. In ${ }^{13} \mathrm{C}-\mathrm{NMR}$ spectra of the compounds, the signal at the lowest field (145-155 ppm) is assigned to the $\mathrm{C} 2$ carbon of the benzimidazole ring in $\mathrm{C}=\mathrm{N}$ form which indicates the formation of the benzimidazole ring system.

\section{CONCLUSIONS}

A simple and efficient methodology for the synthesis of 2-substituted benzimidazoles and bis-benzimidazoles was developed. The reaction times were reduced from hours to minutes by our MWassisted method. Benzimidazoles with different kinds of derivatives were easily synthesized in good yields under neat conditions with an easy purification procedure. 


\section{REFERENCES}

1. Güven, O. O.; Erdoğan, T.; Göker, H.; Yıldız, S.; J. Heterocycl. Chem. 2007, 44, 731.

2. Elnima, E. I.; Zubair, M. U.; Al-Badr, A. A.; Antimicrob. Agents Chemother. 1981, 19, 29.

3. Kazimierczuk, Z.; Upcroft, J. A.; Upcroft, P.; Gorska, A.; Starooeciak B., Laudy A.; Acta Biochim. Pol. 2002, 49, 185.

4. Ahmed, A. El R.; Hassan, Y. A.; Mini-Reviews in Medicinal Chemistry 2013, 13, 399.

5. Soni, B.; Ranawat, M. S.; Bhandari, A.; Sharma, R.; International Journal of Drug Research and Technology 2012, 2, 479.

6. Maxwell W. A.; Brody, G.; Appl. Environ. Microbiol. 1971, 21, 944.

7. Ayhan-Kılcıgil, G.; Altanlar, N.; Turk. J. Chem. 2006, 30, 223.

8. Navarrete-Vázquez, G.; Cedillo, R.; Hernández-Campos, A.; Yépez, L.; Hernández-Luis, F.; Valdez, J.; Morales, R.; Cortés, R.; Hernández, M.; Castillo, R., Bioorg. Med. Chem. Lett. 2001, 11, 187.

9. Cheng, J.; Xie, J.; Luo, X.; Bioorg. Med. Chem. Lett. 2005, 15, 267.

10. Chen, G.; Liu, Z.; Zhang, Y.; Shan, X.; Jiang, L.; Zhao, Y.; He, W.; Feng, Z.; Yang, S.; Liang G.; ACS Med. Chem. Lett. 2013, 4, 69.

11. Terzioğlu, N.; van Rijn, R. M.; Bakker, R. A.; De Esch, I. J. P.; Leurs, R.; Bioorg. Med. Chem. Lett. 2004, 14, 5251.

12. Preston, P. N.; Chem. Rev. 1974, 74, 279.

13. Phillips, M. A.; J. Chem. Soc. 1928, 2393.

14. Ören, I.Y.; Yalçın, I.; Şener, E.A.; Uçartürk, N.; Eur. J. Med. Chem. 2003, 39, 291.

15. Grimmet, M. R.; Best Synthetic Methods-Key Systems and Functional Groups, Imidazole and Benzimidazole Synthesis, Academic Press: San Diego, 1997.

16. Chatterjee, S.; Wolski, J.; J. Indian Chem. Soc. 1966, 43, 660.

17. Lu, J.; Yang, B.; Bai, Y.; Synth. Commun. 2002, 32, 3703.

18. Wang, Y.; Sarris, K.; Sauer, D. R.; Djuric, S. W.; Tetrahedron Lett. 2006, 47, 4823.

19. Zhang, Z. H.; Yin, L.; Wang, Y. M.; Catal. Commun. 2007, 8, 1126.

20. Dudd, L. M.; Venardou, E.; Garcia-Verdugo, E.; Licence, P.; Blake, A. J.; Wilson, C.; Poliakoff, M.; Green Chem. 2003, 5, 187.
21. Cheng, J.; Xiu, N. Y.; Li, X. B.; Luo, X. J.; Synth. Commun. 2005, 35, 2395.

22. Gogoi, P.; Konwar, D.; Tetrahedron Lett. 2006, 47, 79.

23. Triverdi, R.; De, S. K.; Gibbs, R. A.; J. Mol. Catal. 2006, 245, 8.

24. Yadagiri, B.; Lown, J. W.; Synth. Commun. 1990, $20,955$.

25. Lee, K. J.; Janda, K. D.; Can. J. Chem. 2001, 79, 1556.

26. Beaulieu, P. L.; Hache, B.; Von Moos, E.; Synthesis 2003, 11, 1683.

27. Eshghi, H.; Rahimizadeh, M.; Shiri A.; Sedaghat, P.; Bull. Korean Chem. Soc. 2012, 33, 515.

28. Lin, S.; Yang, L.; Tetrahedron Lett. 2005, 46, 4315.

29. Perreux, L.; Loupy, A.; Tetrahedron 2011, 57, 9199.

30. Lidström, P.; Tierney, J.; Wathey, B.; Westman, J.; Tetrahedron 2001, 57, 9225.

31. Ridley, H. F.; Spickett, R. G. W.; Timmis, G. M.; J. Heterocycl. Chem. 1965, 2, 453 .

32. Mukhopadhyay, C.; Tapaswi, P. K.; Tetrahedron Lett. 2008, 49, 6237.

33. Lombardy, R. L.; Tanıous, F. A.; Ramachandran, K., Tidwell, R. R.; Wilson, W. D.; J. Med. Chem. 1996, 39, 1452.

34. Agh-Atabay, N. M.; Dulger, B.; Gucin, F.; Eur. J. Med. Chem. 2003, 38, 875.

35. Phillips, M. A; J. Am. Chem. Soc. 1942, 64, 187.

36. Bahrami, K.; Mehdi Khodaei M.; Naali F.; J. Org. Chem. 2008, 73, 6835.

37. Preston P. N.; The Chemistry of Heterocyclic Compounds: Benzimidazoles and Cogeneric Tricyclic Compounds, John Wiley \& Sons. Inc.: New York, 2009.

38. James, C.; Ravikumar, C.; Jayakumar, V.S.; Hubert Joe, I.; J. Raman Spectrosc. 2009, 40, 537.

39. Klots, T. D.; Devlin, P.; Collier, W. B.; Spectrochim. Acta, Part A 1997, 53,2445 .

40. Sundaraganesan, N.; Ilakiamani, S.; Subramani, P.; Dominic Joshua, B.; Spectrochim. Acta, Part A 2007, 67, 628.

41. Sridharan, V.; Saravanan, S.; Muthusubramanian, S.; Sivasubramanian, S.; Magn. Reson. Chem. 2005, 43, 551.

42. Lee, C. K.; Lee, In-S. H.; Bull. Korean Chem. Soc. 2008, 29, 2205. 